\title{
Prevalence of dermatophytes isolated from domestic animals in Ankara within a three-year period (2014-2017)
}

Nurdan Karacan Sever ${ }^{1}$, Tuğçe Üstün ${ }^{2}$, Mehmed Omerovic ${ }^{2}$, Mustafa Önol ${ }^{2}$, Amir Khazar Zahiri², Barışhan Doğan ${ }^{2}$

${ }^{1}$ Department of Microbiology, Faculty of Veterinary Medicine, Dicle University, Diyarbakır/TURKEY

${ }^{2}$ Department of Microbiology, Faculty of Veterinary Medicine, Ankara University, Ankara/TURKEY

Key Words:

dermatophytosis

domestic animals

Microsporum spp.

Trichophyton spp.

Received : : 30.12 .2020

Accepted : : 07.03.2021

Published Online : 30.04.2021

Article Code : 844656

Correspondence:

NK. SEVER

(nurdankaracan@hotmail.com)

ORCID

NK. SEVER : :0000-0002-0618-5822

T. ÜSTÜN : 0000-0002-1711-5520

M. OMEROVIC : 0000-0002-6578-2627

M. ÖNOL : :0000-0003-4037-7307

AK ZAHIRI: :0000-0003-2020-1160

B. DOĞAN :0000-0002-9151-9232

\begin{abstract}
Dermatophytosis is an infectious and zoonotic disease caused by species belonging to the genera Microsporum, Trichophyton, and Epidermophyton that affects the hair follicles, nails, and keratin layer of the epidermis. The aim of this study was to determine the prevalence of dermatophytosis in different animal species with clinical lesions. To this aim, a total of 395 skin scraping and hair samples taken from cat, dog, horse, parrot, and calf with dermatophytosis suspicion, presented to the Department of Microbiology of Faculty of Veterinary Medicine Ankara University between 2014 and 2017 in different seasons were investigated. A mycological analysis of the samples was conducted involving direct microscopy and a fungal culture test. Of the 395 samples tested, 117 (29.62\%) were positive for dermatophytosis with the following distribution: Microsporum spp., 34 of $195(17.44 \%)$ cats, 24 of $181(13.26 \%)$ dogs, two of 11 (18.18\%) horses; Trichophyton spp., 26 of 181 (14.36\%) dogs, 25 of 195 $(12.82 \%)$ cats, one of $11(9.09 \%)$ horses, one of three $(33.33 \%)$ calves, and two of five $(40 \%)$ parrots; Epidermophyton spp. two of $195(1.02 \%)$ cats. The dermatophyte isolation rate was relatively higher in the summer (36.06\%) and spring $(29.51 \%)$ for cats, and in fall $(30 \%)$ and spring $(26 \%)$ for dogs. As a conclusion, the data contribute to the literature regarding the local epidemiology of dermatophytosis and define potential etiological agents in different animal species, especially cats and dogs.
\end{abstract}

This study was presented as a poster at the '10th Balkan Congress of Microbiology / Microbiologia Balkanica '2017'. November 16th - 18th, 2017, Park Hotel Moskva, Sofia,

Bulgaria

\section{INTRODUCTION}

Dermatophytosis (ringworm) is the superficial infection of such keratinized tissue as the nails/claws, hair and stratum corneum caused by the Microsporum, Trichophyton, and Epidermophyton genera of fungi (1-4). Affecting several mammalian species, including humans and poultry, dermatophytes are classified as anthropophilic (mostly humanassociated), zoophilic (animal-associated) and geophilic (soildwelling) based on their natural habitat and host preferences $(2,3,5)$. Mostly zoophilic and geophilic species, and more rarely anthropophilic species, have been reported to cause infections in animals (1,5-7). Dermatophytes are known to be among the most common causes of dermatological problems in domesticated animals, and have also been reported to cause serious infections especially in the immunocompromised (AIDS, organ transplantation, diabetes mellitus, etc.) in many countries around the world (4,8-10). Dermatophytosis is considered a significant disease in veterinary medicine, due to its contagiousness and zoonotic potential, and in pet veterinary medicine in particular. Several mammals and poultry species are susceptible to infection, regardless of age, gender or breed, although it is inclined to occur more often in young, sick, and elderly patients. The incidence of dermatophytosis varies in terms of the natural host, climatic conditions, and geographical differences $(1-3,6)$.

While there are more than 30 species that are known to cause dermatophytosis, it is believed that Microsporum (M) canis, M. gypseum, and Trichophyton $(T)$ mentagrophytes are responsible for dermatophytosis in cats and dogs, $T$. verrucosum in cattle and other ruminants, $M$. canis and $T$. equinum in horses and $M$. gallinae in poultry $(1,3,5,11)$. Transmission occurs primarily through direct contact with dermatophyte-infected animals or with contaminated fomites (via brushes, soil, etc). Germination occurs through the adherence of dermatophyte arthrospores to the cells of the stratum corneum, producing hyphae that then invade the stratum corneum through keratinases. Invasion induces an immune response, and the typical clinical presentation emerges within 1-3 weeks of exposure to the agent $(5,10,12)$. Clinical presentations that may indicate dermatophytosis include such symptoms as 
alopecia, erythema, papules, scaling, and crusting, either individually or in combination $(2,3,13)$. The clinical course and clinical signs of dermatophytosis contribute substantially to laboratory diagnosis, which is established through the direct microscopy of suspected samples and the subsequent isolation and identification of dermatophytes in cultures $(9,13)$.

This study aimed to examine the samples of different animal species sent to the Department of Microbiology of Faculty of Veterinary Medicine Ankara University with suspected dermatophytosis between 2014 - 2017 and to determine the seasonal isolation rates.

\section{MATERIAL and METHODS}

A total of 395 skin scrapings and hair samples from 195 cats, 181 dogs, 11 horses, five parrots, and three calves that presented to the Department of Microbiology of Faculty of Veterinary Medicine Ankara University with suspected dermatophytosis in various seasons were investigated between 2014 and 2017.

\section{Direct microscopic examination}

The suspected skin scraping and hair samples were mixed with $10 \%$ potassium hydroxide $(\mathrm{KOH})$ (Merck, Germany) in preparation for analysis. After being kept at room temperature for 15-20 minutes, the preparations were examined by lightmicroscope at 40x magnification to screen for hyphae and dermatophyte spores $(9,14)$.

\section{Mycological isolation}

The suspected dermatophyte suspected samples were cultured in a Sabouraoud Dextrose Agar (SDA) medium (Oxoid, UK) supplemented with chloramphenicol (Oxoid, $\mathrm{UK})(0.05 \mathrm{mg} / \mathrm{ml})$, after being embedding using a sterile pen or lancet. The media was incubated under aerobic conditions and at $25^{\circ} \mathrm{C}$ for $1-4$ weeks, and checked on a daily basis $(9,14)$.

\section{Macroscopic and microscopic examination of fungal colonies}

The macroscopic examination was completed upon the evaluation of growing status and the time, shape, and pigmentation characteristics of the front and rear surfaces of the colonies, within and at the end of the incubation period. A microscopic examination was made to identify dermatophyte species in the hyphae, macroconidia, and microconidia on preparations made through the cellophane band method using a lactophenol cotton blue solution (Merck, Germany) (13,14).

\section{Statistical analysis}

The chi-square $\left(x^{2}\right)$ test was used to examine the statistical significance of distribution of dermatophyte species and dermatophytosis prevalence in the population analyzed, distribution of dermatophyte species according to animal species, and dermatophytosis prevalence by seasons. $p<0.001$ was considered statistically significant. The IBM SPSS Statistics V21.0 software package for Windows was used for the statistical analyses.

\section{RESULTS}

Of the 395 examined samples obtained from the various animal species, $117(29.62 \%)$ were positive for dermatophytosis, and $60(51.29 \%)$ isolates were identified as Microsporum spp., $55(47 \%)$ as Trichophyton spp., and two $(1.71 \%)$ as Epidermophyton spp., being the difference significant $\left[\mathrm{x}^{2}(\mathrm{df}=3, \mathrm{n}=395)=454,752(p<0.001)\right]$ (Table 1). The distribution isolated dermatophytes and animal species was presented in Table 2 . No statistically significant difference $(p$ $<0.001)$ was detected among the animal species in terms of the identified dermatophyte species. The seasonal distribution of dermatophytosis indicated a proportionate increase in the summer months in cats $(36.06 \%)$ and calves (100\%), and in fall in dogs $(30 \%)$ and horses $(66.67 \%)$, while it was equally distributed across the fall and winter months for parrots (Table $3)$. No statistically significant association $(\not<0.001)$ was found in the seasonal distribution of animal dermatophytoses.

Table 1. Distribution of results of samples examined according to animal specie.

\begin{tabular}{lcc} 
Animal species & Materials (\%) & Positive (\%) \\
\hline Cat & $195(49.37)$ & $61(31.28)$ \\
Dog & $181(45.82)$ & $50(27.62)$ \\
Horse & $11(2.79)$ & $3(27.27)$ \\
Parrot & $5(1.26)$ & $2(40)$ \\
Calf & $3(0.76)$ & $1(33.33)$ \\
Total & $395(100)$ & $117(29.62)$ \\
\hline
\end{tabular}

Table 2. Number and frequency of dermatophytes isolated from different animal species.

\begin{tabular}{|c|c|c|c|c|c|c|}
\hline & Cat & Dog & Horse & Parrot & Calf & Total \\
\hline Dermatophytes & \multicolumn{6}{|c|}{ n $(\%)$} \\
\hline Microsporum spp. & $34(55.74)$ & $24(48)$ & $2(66.67)$ & - & - & $60(51.29)$ \\
\hline Trichophyton spp. & $25(40.98)$ & $26(52)$ & $1(33.33)$ & $2(100)$ & $1(100)$ & $55(47)$ \\
\hline Epidermophyton spp. & $2(3.28)$ & - & - & - & - & $2(1.71)$ \\
\hline Total & $61(52.14)$ & $50(42.74)$ & $3(2.56)$ & $2(1.71)$ & $1(0.85)$ & $117(100)$ \\
\hline
\end{tabular}


Table 3. Seasonal distribution of dermatophytes isolated from different animal species.

\begin{tabular}{lcccccc}
\hline & Cat & Dog & Horse & Parrot & Calf & Total \\
\cline { 2 - 7 } Seasons & & \multicolumn{7}{c}{$\mathrm{n}(\%)$} \\
\hline Winter & $8(13.11)$ & $10(20)$ & - & $1(50)$ & - & $19(16.24)$ \\
Spring & $18(29.51)$ & $13(26)$ & $1(33.33)$ & - & - & $32(27.35)$ \\
Summer & $22(36.06)$ & $12(24)$ & - & - & $1(100)$ & $35(29.91)$ \\
Fall & $13(21.31)$ & $15(30)$ & $2(66.67)$ & $1(50)$ & - & $31(26.49)$ \\
\hline
\end{tabular}

\section{DISCUSSION}

Dermatophytes are known to be among the most common causes of dermatological problems in domesticated animals and dermatophytosis are common in many countries around the world. Several studies are available on dermatophytosis in various animal species as varying. In a study in Finland, Aho (1980) reported a positivity rate of $10.9 \%$ for dermatophytes in 331 samples collected from various animals $3.9 \%$ of dogs, $21.3 \%$ of cats, $14.8 \%$ of cows, and no cage birds) with suspected dermatophytosis (15). Cabanes et al. (1997) reported a positivity rate of $33.7 \%$ for dermatophytes in 270 samples (38.9\% of dogs, $33.9 \%$ of cats, $23.1 \%$ of horses, $25 \%$ of cows, and no parrots) in Spain (16). The several researchers indicated that $31.4 \%$ of 790 and $35.7 \%$ of 487 samples to be positive for dermatophytosis $(55 \%$ of feline, $8 \%$ of canine, $38 \%$ of bovine, $19 \%$ of equine and $21.6 \%$ of canine, $43.5 \%$ of feline, $100 \%$ of bovine, $40 \%$ of equine samples, repectively) in Iran $(17,18)$. In Nigeria, Nweze $(2011)$ reported that $39.8 \%$ of 538 samples were positive for dermatophytosis, with an animal origin-based rate of dermatophyte positivity of $22 \%$ in cats, $24.3 \%$ in dogs, $12.6 \%$ in cows, and $5.1 \%$ in horses (7).

The isolation of Microsporum spp. and Trichophyton spp. in various animal species (cat, dog, horse, and cow) ranges between $71-90 \%$ and $52-74 \%$, respectively $(7,17-19)$. Cabanes et al. (1997) reported that Microsporum spp. and Trichophyton spp. isolation rates were $48.27 \%$ and $20.41 \%$ in same animal species (16). A comparison of the isolation rates established in the present study with those reported by the abovementioned studies reveals higher rates than those reported by Cabanes et al. (1997) and lower rates than those reported by Khosravi and Mahmoudi (2003), Yahyaraeyat et al. (2009), Nweze (2011), and İlhan (2015) (7, 17-19). In addition, the study findings were determined to be similar to the study findings (50\% for Microsporum spp. and $41.67 \%$ for Trichophyton spp.) reported by Aho (1980) (15). It was considered that the differences in dermatophyte isolation rate might have resulted from the variability in animal breeds, and the quantities of samples collected.

It is reported that more than $95 \%$ of cases of dermatophytosis in cats are caused by Microsporum and Trichophyton species, and in particular, M. canis. Epidermophyton species among the anthropophilic dermatophytes have been reported to cause infections in animals on rare occasions $(1,4,6)$. In the study, $55.74 \%$ of the $61(31.28 \%)$ dermatophyte agents isolated from 195 suspected cat samples were identified as Microsporum spp. and $40.98 \%$ as Trichophyton spp. When compared with studies conducted in different regions of Turkey and the other countries, these rates are lower for Microsporum spp. and higher for Trichophyton spp. (19-29). Furthermore, 3.28\% of the dermatophyte isolates were identified as Epidermophyton spp. in present study. The isolation of Epidermophyton spp. from animals reflected the human flora rather than the infection, while there are rare cases indicating infections in immunocompromised dogs (2). In our knowledge there was no reports of Epidermophyton spp. in animals in Turkey.

As with the case for cats, reports indicate that the causative agent of dermatophytosis in dogs are such Microsporum and Trichophyton species as T. mentagrophytes and M. gypseum, and in particular, $M$. canis $(1,2,4)$. In the study, $48 \%$ of the 50 dermatophyte agents $(27.62 \%)$ isolated from 181 dermatophytosis suspected dog samples were identified as Microsporum spp. and 52\% as Trichophyton spp. Unlike cats, the rate of Microsporum spp. isolates in dogs was found to be lower than the rate of Trichophyton spp. isolates in the present study. Trichophyton spp. is known to be dominant in the back of dogs (27). It was considered that high Trichophyton spp. isolation in dogs may be related to the sampling area in this study. It has been ascertained from the studies carried out in several different parts of Turkey and around the world that species of the genus Microsporum account for the majority of dermatophytes isolated from dogs $(21,24,26,28-32)$. In this regard, the findings of the present study differ from those of the aforementioned studies, while our study findings share similarities with those reported by Derincegöz and Parın (2016) in Turkey (Trichophyton spp. in 57.14\% and Microsporum spp. in $42.86 \%$ of the isolates) and by Beraoldo et al. (2011) in Brazil (Trichophyton spp.in 57.89\% and Microsporum spp. in $42.11 \%)(23,27)$.

It is reported that dermatophytosis in horses is caused by Trichophyton and Microsporum species, and in particular, such as T. equinum, M. canis, T. mentagrophytes, and T. verrucosum $(3,4,11)$. It has been indicated that the isolation of Trichophyton spp. and Microsporum spp. in suspected horse samples ranges between $50-100 \%$ and $25-50 \%$, respectively $(7,15,16,33-36)$. The isolation rate of Microsporum spp. in the present study was higher and the isolation rate of Trichophyton spp. was lower than those reported by the mentioned studies, but similar to those reported in the study by Khosravi and Mahmoudi (2003) conducted in Iran involving 79 horses (33.33\% for Trichophyton spp., $66.67 \%$ for Microsporum spp.) (17). We believe that this difference might be a result of limited number of horse-origin 
samples assessed.

It has been indicated that dermatophytosis in ruminants is caused by Trichophyton and Microsporum species, such as T. mentagrophytes, T. equinum, $M$. canis, and M. gypseum, and in particular T. verrucosum $(1,2,4)$. In many studies, the researchers reported that that all of the dermatophytes isolated from calfand cow-origin samples were species belonging to the genus Trichophyton, and in particular, T. verrucosum (15,17,19,37-41). In addition, Neweze (2011) reported that Trichophyton spp. and Microsporum spp. isolation rates were $59.26 \%$ and $40.74 \%$ in 55 samples collected from cows in a study in Nigeria (7). It was used a small number of samples calf in the study. However, it can be considered that the study findings $(100 \%$ for Trichophyton spp.) similar to the mentioned study findings in terms of the Trichophyton spp. isolation.

Literature indicates that dermatophytosis is rare in poultry, and is usually reported only as sporadic cases. It is thought that M. gallinae is responsible for dermatophytosis in poultry, in additional, T. simii, T. mentagrophytes and T. terrestre have also been reported to cause infection $(1,2)$. Trichophyon spp. from two $(40 \%)$ of the five parrot-origin samples were isolated in present study. The dermatophytosis studies in domesticated or wild birds are limited. The study by Cabanes et al. (1997), conducted with different animal species in Spain, reported that no dermatophyte agent was isolated from the samples collected from a parrot, while Gungnani et al. (2012) from Saint Kitts and Nevis reported isolating $M$. gypseum from samples collected from brown doves, pigeons, and ducks, but no isolation of dermatophyte agents from parrot-origin samples $(16,42)$. Furthermore, the study by Mandeel et al. (2009), conducted with clinically healthy birds in Bahrain, reported the collection of two $T$. terrestre isolates from five Alexandrian parrot samples (43). Alteraş and Cojoca (1970) reported the isolation and identification of $M$. canis from a parakeet and the owner of the bird in Romania (44). The fact that dermatophytes were isolated from parrot samples in this study and that these isolates belong to the Trichophyton species are similar to be the findings of Mandeel et al. (2009) (43). In addition, it is considered to the findings provide a significant contribution to literature given the limited number of studies in this field to date.

The prevalence of dermatophytosis in cats and dogs is known to vary by location and season due to differences in climatic conditions $(26,29)$. There have been several reports in this regard in many countries around the world and different parts of Turkey $(16,17,21,22,24,26,29,31)$. Although the seasonal distribution did not indicate a significant association with dermatophytosis, the present study established an increased rate of feline dermatophytosis in summer (36.06\%) and spring $(29.51 \%)$, and canine dermatophytosis in fall (30\%) and spring $(26 \%)$, differing from the study by Çiftçi et al. (2005) that was carried out in the same region, but in a different year (22).

\section{CONCLUSION}

In the present study, it was determinated that Microsporum spp. was the most common species isolated from the samples belong to different animal species and the isolation rates of dermatophytes may differ according to the season and animal species. It was considered that Epidermophyton spp. isolation from cats is valuable finding in terms of transmission of dermatophytes to animal from human. There have been a number of studies of feline and canine dermatophytoses in Turkey, but few reports about the other animal species as poultry etc. Based on the results, it is suggested that the identification of other animal species that are prone to dermatophytosis infection, and that are in close contact with humans, is important for both animal and human health. Furthermore, laboratory diagnoses should be obtained in cases of suspected dermatophytosis, and it would be beneficial to raise awareness among animal owners and animal keepers of this issue due to the potential for zoonotichumans, is important for both animal and human health. Furthermore, laboratory diagnoses should be obtained in cases of suspected dermatophytosis, and it would be beneficial to raise awareness among animal owners and animal keepers of this issue due to the potential for zoonotic transmission.

\section{DECLARATIONS}

\section{Ethics Approval}

Not applicable.

\section{Conflict of Interest}

The authors declare that they have no competing interests.

\section{Author Contribution}

Idea, concept and design: N Karacan-Sever,

Data collection and analysis: N Karacan-Sever, T Üstün, M Omerovic, M Önol, AK Zahiri, B Doğan

Drafting of the manuscript: $\mathrm{N}$ Karacan-Sever

Critical review: N Karacan-Sever, T Üstün, M Omerovic, M Önol, AK Zahiri, B Doğan

\section{Data Availability}

The data that support the findings of this study are available from the corresponding author upon reasonable request.

\section{Acknowledgements}

Thanks to Prof. Dr. Müjgan İzgür (Ankara University, Faculty of Veterinary Medicine, Department of Microbiology, Ankara, Turkey/ retired lecturer) for her constructive suggestions during development of the study and Işiner Sever, PhD for statistical analyses.'

\section{REFERENCES}

1. Cabanes FJ. Dermatophytes in domestic animals. Rev Iberoam Micol. 2000;17:104-8.

2. Chermette R, Ferreiro L and Guillot J. Dermatophytoses in animals. Mycopathologia. 2008;166(5-6):385-405.

3. Bond R. Superficial veterinary mycoses. Clin Dermatol. 2010;28:226-236.

4. Moretti A, Agnetti F, Mancianti F, Nardoni S, Righi C, Moretta I, et al. Epidemiological, clinical and zoonotic aspects. G Ital Dermatol Venereol. 2013;148(6):563-72.

5. Moriello KA, Coyner K, Paterson S, Mignon B. Diagnosis and treatment of dermatophytosis in dogs and cats. Clinical 
Consensus Guidelines of the World Association for Veterinary Dermatology. Vet Dermatol. 2017;28(3):266-e68.

6. Mattei AS, Beber MA, Madrid IM. Dermatophytosis in small animals. SOJ Microbiology \& Infectious Diseases. 2014;2:1-6.

7. Nweze EI. Dermatophytoses in domesticated animals. Rev Inst Med Trop Sp. 2011;53(2):94-99.

8. Rinaldi MG. Dermatophytosis: epidemiological and microbiological update. J Am Acad Dermatol. 2000;43(5Suppl):S120-S124.

9. Robert R, Pihet M. Conventional methods for the diagnosis of dermatophytosis. Mycopathologia. 2008;166(56):295-306.

10. Gnat S, Nowakiewicz A, Lagowski D, Zięba P. Hostand pathogendependent susceptibility and predisposition to dermatophytosis. J Med Microbiol. 2019;68(6):823-836.

11. Cafarchia C, Figueredo LA, Otranto D. Fungal diseases of horses. Vet Microbiol. 2013;167(1-2):215-234.

12. Vermout S, Tabart J, Baldo A, Mathy A, Losson B, Mignon B. Pathogenesis of dermatophytosis. Mycopathologia. 2008;166(5-6):267-75.

13. Markey B, Leonard F, Archambault M, Cullinane A, Maguire D. Section 3: Mycology. Chapter 38. In: Edwards R, Hewat C, editors. Clinical Veterinary Microbiology. 2th. ed. Missouri, USA: Mosby Elsevier; 2013. p. 471-480.

14. Arda M. Mantarlarnn genel karakterleri. In: Arda M. editör. Temel Mikrobiyoloji. Genişletilmiş 2. Bask1, Ankara, Türkiye: Medisan Yayınevi; 2000. p. 315-367.

15. Aho R. Studies on fungal flora in hair from domestic and laboratory animals suspected of dermatophytosis. 1. Dermatophytes. Acta Path Microbiol Scand. Sect B. 1980;88(2):79-83.

16. Cabanes FJ, Abarca ML, Bragulat MR. Dermatophytes isolated from domestic animals in Barcelona, Spain. Mycopathologia. 1997;137:107-113.

17. Khosravi AR, Mahmoudi M. Dermatophytes isolated from domestic animals in Iran. Mycoses. 2003;46:222-225.

18. Yahyaraeyat R, Shokri H, Khosravi AR, Soltani M, Erfanmanesh A, Nikaein D. Occurrence of animals dermatophytosis in Tehran, Iran. J Zool. 2009;4(3):200-204.

19. Illhan Z. Isolation of dermatophytes from cattle, sheep, goats and Van cats in Van and its around. Van Vet J. 2015;26(1):1-5.

20. Selvi BI, Yildirım M. Isolation of dermatophytes from cats and dogs in Ankara. Eurasian J Vet Sci. 2019;35(3):170174.

21. Seker E, Dogan N. Isolation of dermatophytes from dogs and cats with suspected dermatophytosis in Western Turkey. Prev Vet Med. 2011;98(1):46-51.
22. Çiftçi A, Iça T, Sareyyüboğlu B, Müştak HK. Kedi ve köpek dermatofitozlarından izole edilen mantarların retros-pektif değerlendirilmesi. Ankara Üniv Vet Fak Derg. 2005;52:45-48.

23. Derincegöz Z, Parın U. Kedi ve köpeklerde deri lezyonlarindan dermatofit etkenlerinin izolasyonu. Animal Health, Prod and Hyg. 2016;5(1):410-415.

24. Yapıcıer ÖŞ, Şababoğlu E, Öztürk D, Pehlivanoğlu F, M Kaya Türütoğlu H. Kedi ve köpeklerden dermatofitlerin izolasyonu. MAE Vet Fak Derg. 2017;2(2):125130.

25. Sığırcı BD, Metiner K, Çelik B, Kahraman BB, İkiz $\mathrm{S}$, Bağcigil AF, et al. Dermatophytes isolated from dogs and cats suspected dermatophytoses in Istanbul, Turkey within a 15-year-period: An updated report. Kocatepe Vet J. 2019;12(2):116-121.

26. Cafarchia C, Romito D, Sasanelli M, Lia R, Capelli G, Otranto D. The epidemiology of canine and feline dermatophytoses in southern Italy. Mycoses. 2004;47(1112):508-513.

27. Beraldo RM, Gasparoto AK, de Siqueira AM, Dias ALT. Dermatophytes in household cats and dogs. Rev Bras Med Vet. 2011;18(2/3):85-91.

28. Murmu S, Debnath C, Pramanik AK, Mitra T, Jana $\mathrm{S}$, Dey $\mathrm{S}$, et al. Detection and characterization of zoonotic dermatophytes from dogs and cats in and around Kolkata. Vet World. 2015;8(9):1078-1082.

29. Mancianti F, Nardoni S, Cecchi S, Corazza M, Taccini F. Dermatophytes isolated from symptomatic dogs and cats in Tuscany, Italy during a 15-year-period. Mycopathologia. 2003;156(1):13-18.

30. Tel OY, Akan M. Kedi ve köpeklerden dermatofitlerin izolasyonu. Ankara Üniv Vet Fak Derg. 2008;55:167-171.

31. Babacan O, Baş B, Müştak HK, $\square$ ahan O, Tekin O, Torun E. Retrospective evolution of dermatophytes isolated from cats and dogs. Etlik Vet Mikrobiyol Derg. 2011;22:23-26.

32. Roshanzamir H, Naserli S, Ziaie B, Fakour M. Incidence of dermatophytes isolated from dogs and cats in the city of Baku, Azerbaijan. Comp Clin Path. 2016;25:327-329.

33. Maurice MN, Kazeem HM, Kwanashie CN, Maurice NA, Ngbede EO, Adamu HN, et al. Equine dermatophytosis: a survey of its occurrence and species distribution among horses in Kaduna State, Nigeria. Scientifica. 2016;2016:6280646.

34. ElAshmawy WR, Ali ME. Identification of different dermatophytes isolated from cattle, cats and horses suffered from skin lesions. Alex J Vet Sci. 2016;49(2):126-132.

35. Ahdy AM, Sayed-Ahmed MZ, Younis EE, Baraka HN, El-khodery SA. Prevalence and potential risk factors of dermatophytosis in Arabian horses in Egypt. J Equine Vet Sci. 2016;37:71-76.

36. Yahyaei M, Ebrahimi MM. Survey on horse 
dermatophytosis in Golestan, Iran. Arch Razi Inst. 2000;51:137-41.

37. Al-Qudah KM, Gharaibeh AA, Maysa'a M. Trace minerals status and antioxidant enzymes activities in calves with dermatophytosis. Biol Trace Elem Res. 2010;136:40-47.

38. Dalis JS, Kazeem HM, Kwaga JKP, Kwanashie CN. An outbreak of ringworm caused by Trichophyton verrucosum in a group of calves in Vom, Nigeria. Afr J Microbiol Res. 2014;8(8):783-787.

39. Golah HAM, Khalel AS, Khaled JMA, Shine K. Antifungal susceptibility of dermatophytes isolated from domestic calves in Thamar, Yemen. J Anim Vet Adv. 2012;11(24):4544-4548.

40. Özkanlar Y, Aktaş MS, Kireçci E. Mycozoonosis associated with ringworm of calves in Erzurum Province, Turkey. Kafkas Univ Vet Fak Derg. 2009;15(1):141-144.

41. Papini R, Nardoni S, Fanelli A, Mancianti F. High infection rate of Trichophyton verrucosum in calves from Central Italy. Zoonoses Public Hlth. 2009;56(2):5964.

42. Gungnani HC, Sharma S, Gupta B. Keratinophilic fungi recovered from feathers of different species of birds in $\mathrm{St}$ Kitts and Nevis. W Indian Med J. 2012;61(9):912915.

43. Mandeel Q, Nardoni S, Mancianti F. Keratinophilic fungi on feathers of common clinically healthy birds in Bahrain. Mycoses. 2011;54:71-77.

44. Alteraş, I, Cojocaru I. Microsporum gypseum infection in the parrot (Melopsittacus undulatus). Mycoses. 1970;13:377-379. 